\title{
ADDENDUM TO "PRACTICAL AND MATHEMATICAL ASPECTS OF THE PROBLEM OF RECONSTRUCTING OBJECTS FROM RADIOGRAPHS”
}

\author{
BY KENNAN T. SMITH, DONALD C. SOLMON, AND SHELDON L. WAGNER
}

Two important references were omitted from this article. The theorem on the convergence of iterated projections which was credited to Amemiya and Ando was proved first by I. Halperin [1]. The theorem characterizing the range of the Radon transform which was credited to D. Ludwig was obtained first by $S$. Helgason [2], [3].

AMS (MOS) subject classifications (1970). Primary 92A05, 78A55; Secondary 44A15.

\section{REFERENCES}

1. I. Halperin, The product of projection operators, Acta. Sci. Math. 23 (1962), 96-99.

2. S. Helgason, A duality in integral geometry; some generalizations of the Radon transforms, Bull. Amer. Math. Soc. 70 (1964), 435-446.

3. __ The Radon transform on Euclidean spaces, compact two-point homogeneous spaces, and Grassmann manifolds, Acta Math. 113 (1965), 153-180.

Department of Mathematics, Oregon State University, Corvallis, Oregon 97331 
